ECONOmía TeORía y PrÁctica • Nueva Época, número especial, agosto 2018, pp. 215-244,

http://dx.doi.org/10.24275/ETYPUAM/NE/E042018/Mora

\title{
Pobreza y hogares receptores de remesas a veinte años del TLCAN: México 2010, 2012 y 2014*
}

\section{Poverty and Remittance Receiver Households After Twenty Years of NAFTA: Mexico 2010, 2012 and 2014}

\author{
Jorge Mora-Rivera, ** Ignacio Llamas Huitrón*** \\ y Martha Cecilia Garcia Amador****
}

\begin{abstract}
RESUMEN
En este artículo se analiza la situación de los hogares por condición de remesas y la dinámica que han presentado en sus indicadores de pobreza en los años 2010, 2012 y 2014, con el fin de identificar algunos posibles efectos positivos que ha generado la apertura comercial incentivada por el TLCAN. Para ello, se construyó una base de datos propia con base en la información del Módulo de Condiciones Socioeconómicas de la ENIGH. Se encontró que los hogares que reciben remesas internacionales presentan una disminución de sus niveles de pobreza en los años analizados a diferencia de aquellos hogares que no reciben remesas y los que reciben remesas nacionales. Si bien este resultado permite inferir que las remesas internacionales han contribuido a mejorar la condición de los hogares en situación de pobreza, en este artículo no se utilizan estimaciones de causalidad, puesto que van más allá del objeto central del análisis realizado; sin embargo, abren la posibilidad para futuras investigaciones que podrían apoyar y robustecer el presente estudio.
\end{abstract}

Palabras clave: Migración; remesas; pobreza; TLCAN.

Clasificación JEL: F24, I32, O10, F22.

\begin{abstract}
The purpose of this paper is to identify some possible effects of NAFTA's trade openness on the reception of remittances and poverty indexes of Mexican Households in 2010, 2012, and 2014. We built a database for 2010, 2012, and 2014 using information from the Module of Socioeconomic Conditions of the National Survey of Mexican Household Income and Expenditure (Módulo de Condiciones Socioeconómicas, ENIGH). Remittance receiver households showed lower levels of poverty indexes than households not receiving remittances and households receiving national transferences. This suggests that remittances help to improve the economic situation of poor households. However, more research is needed on this topic before we can arrive at the conclusion that remittances are a means to get households out of poverty.
\end{abstract}

Key words: Migration; Remittances; Poverty; NAFTA.

JEL Classification : F24, I32, O10, F22.

* Fecha de recepción: 23-07-2017. Fecha de aprobación: 16-02-2017.

** Tecnologico de Monterrey, Campus Ciudad de México. Correo: jjmora@itesm.mx. oRCID: 0000-0003-0838-9551

*** Universidad Autónoma Metropolitana, Unidad Iztapalapa. Correo: 1lamas.huitron@ hotmail.com. ORCID: 0000-0003-0554-0797

**** Universidad Autónoma Metropolitana, Unidad Iztapalapa. Correo: cecilia.garcia. amador@gmail.com. ORCID: 0000-0001-6076-7375 


\section{INTRODUCCIÓN}

La puesta en marcha del Tratado de Libre Comercio de América del Norte (TLCAN) generó en México expectativas positivas de crecimiento a partir de los beneficios que este tratado podría generar. Se esperaba que el TLCAN ocasionara un incremento de la inversión extranjera directa, una reducción de la brecha de los salarios México-Estados Unidos, un aumento en las exportaciones que desencadenaran un balance comercial favorable para el país, mejoras en los sectores turístico, petrolero y manufacturero, así como pérdidas en la agricultura. En materia de migración se esperaba que a raíz de la mejora en los salarios reales hubiera una baja en los montos totales de migrantes. Sin embargo, a más de 20 años de la puesta en marcha del TLCAN, sus beneficios económicos no son los esperados. Los principales problemas se pueden observar en la incapacidad de los sectores productivos para generar el volumen de empleo que demanda la dinámica poblacional, en el acentuado deterioro que presentan los salarios reales (Herrera, 2016; Mendoza y Calderón, 2006), así como en el incremento de la informalidad (Díaz, 2009). Sin embargo, un efecto positivo lo constituye el incremento en la Inversión Extranjera Directa (IED), en las exportaciones y en la recepción de remesas. Estas últimas benefician y son indispensables para un segmento importante de la población; además, son el centro de análisis de esta investigación.

Las remesas son una consecuencia fundamental de la migración. A la vez, el envío de dinero de los migrantes repercute en el desarrollo de la economía de su región de origen (Adams, 2011). La importancia de las remesas se puede observar en diversos indicadores de desarrollo, tales como el nivel de ingreso y gasto, y en mejoras en las condiciones generales de vida de los hogares (Mora y Arellano, 2016; Yang, 2011).

En 2015, México fue el segundo país expulsor de migrantes en el mundo, acumulando un total de 12.3 millones de mexicanos viviendo en el exterior, cifra que representaba un 5.1 por ciento del total mundial (BBVA, 2017). Así mismo, y a partir de $1995,{ }^{1}$ el incremento en el monto de las remesas a nivel mundial ha sido considerablemente alto, al pasar de 97.9 mil millones de dólares a 588.2 mil millones en 2015. Así, México se encuentra entre los cuatro primeros países receptores de remesas, sólo por debajo de India, China y Filipinas, con aproximadamente un 4.4 por ciento de remesas del total mundial (BBVA, 2016).

Los estudios realizados acerca del efecto que las remesas tienen en el desarrollo de los hogares y regiones que las reciben difieren en sus conclusiones al respecto.

${ }^{1}$ Después de la entrada en vigor del TLCAN. 
Por ejemplo, las investigaciones del papel que juegan las remesas en indicadores de pobreza en los hogares receptores pueden dividirse en dos grandes vertientes. Por un lado, están aquellos que concluyen que las remesas no tienen un impacto significativo en la reducción de la pobreza (Canales, 2006; Olivié et al., 2008). Por el otro, están quienes encuentran un impacto positivo de las remesas en la disminución de los niveles de pobreza (Mora y López, 2010; Adams y Page, 2005), es decir, que las remesas que reciben los hogares han ayudado a incrementar su nivel de ingreso y con ello a mejorar sus condiciones de vida.

El objetivo de esta investigación es presentar la evolución, en los últimos años, de los niveles de pobreza de los hogares que reciben remesas nacionales e internacionales, así como sus características sociodemográficas y las carencias correspondientes a la pobreza multidimensional que padecen, con el fin de identificar algunas de las consecuencias que, de manera colateral, se pudieron generar con la puesta en marcha del TLCAN. Así, el presente análisis pretende identificar evidencia que apoye alguna de las dos diferentes posiciones planteadas en la literatura respecto a las implicaciones de las remesas en la pobreza.

Esta investigación contribuye a llenar el vacío que ocasiona la falta de un análisis dinámico de la situación de pobreza asociada a los hogares receptores de remesas, tema que ha estado ausente en la literatura especializada. Algunas de las ventajas de esta investigación respecto a las existentes son las siguientes. En primer lugar, ofrece un análisis para varios años que permite una visión más comprensiva de la evolución de los niveles de pobreza que enfrentan los hogares receptores de remesas, nacionales e internacionales. En segundo lugar, en esta investigación se usa la metodología oficial de pobreza multidimensional y los datos del Módulo de Condiciones Socioeconómicas (MCS) en los cálculos efectuados. Si bien los trabajos de Pardo y Dávila (2017), Mora y Arellano (2016), y García-Zárate (2015) abordan a los hogares receptores de remesas nacionales e internacionales, no utilizan esta fuente de información; en dichos estudios se usan datos de la Encuesta Nacional de Ingresos y Gastos de los Hogares (ENIGH), y sólo la última investigación aborda temas relacionados con la pobreza en los hogares receptores de remesas.

Este trabajo se divide en cinco apartados, incluyendo la introducción. En el segundo se presenta el marco teórico que rige y da sustento al análisis efectuado. En el tercero se aborda la importancia de la migración y las remesas en el desarrollo económico y ofrece un panorama general de los hogares después de la firma del TLCAN. En el cuarto se describen los datos y el diseño de la investigación, el cual, a su vez, se divide en cuatro subapartados que presentan los distintos cálculos y el análisis estadístico de este trabajo. Las reflexiones finales se incluyen en el quinto y último apartado. 


\section{RESTRICCIONES DE MERCADO, REMESAS Y LA NUEVA ECONOMÍA DE LA MIGRACIÓN}

Una amplia gama de trabajos sobre migración sienta las bases para describir los patrones observados en los movimientos poblacionales y estudiar los principales determinantes de la migración (Massey, 2015; Massey et al., 1993). Sin embargo, varias de estas investigaciones tienden a estudiar el fenómeno en sí mismo o a analizar su impacto total en la economía, descuidando los impactos que el fenómeno migratorio tiene en los hogares y las comunidades de origen de los migrantes.

Una de las diferencias más importantes entre los modelos neoclásicos de migración y los de la nueva economía de la migración laboral (NELM, por sus siglas en inglés) es la unidad de análisis. Los primeros (por ejemplo, Todaro, 1969; Harris y Todaro, 1970) consideran las decisiones de migración desde una perspectiva individual, ignorando uno de los principales motivos de la migración, a saber: el compartir parte del ingreso de los migrantes con sus hogares de origen.

Por su parte, la NELM argumenta que las decisiones de migrar se toman en un contexto que involucra acuerdos familiares, es decir, que las personas toman resoluciones de manera colectiva y en el plano del hogar, con el objetivo de maximizar el ingreso familiar, minimizar los riesgos y disminuir las restricciones creadas por diversas fallas del mercado, adicionales a las del mercado de trabajo (Stark, 1991).

Esta teoría identifica a la fuente de la decisión migratoria no en el agente individual maximizador, sino en el hogar, la familia que construye la estrategia de la migración de algunos de sus miembros, con el propósito no sólo de maximizar ingresos, sino de diversificar sus fuentes de recursos y reducir los riesgos económicos (Massey et al., 1993). En la medida en que la finalidad de la migración no sólo es maximizar los ingresos en términos absolutos, sino que también considera la posición del hogar respecto a los hogares en su grupo de referencia, se retoma así la noción de privación relativa (Stark, 1991). Entonces, cuanto más desigual sea la distribución del ingreso en una comunidad determinada, más se sentirá la privación relativa y mayores serán los incentivos para la migración.

Las hipótesis planteadas por la NELM reconocen que los migrantes no rompen los vínculos con sus lugares de origen. Por el contrario, los miembros del hogar que permanecen en el lugar de origen tienden a reorganizar sus patrones de consumo y sus actividades productivas en función del comportamiento de los miembros migrantes del hogar, ya que éstos comparten parte de sus ingresos con sus familiares que permanecen en el hogar (Mora y Arellano, 2016; Taylor, 1999). Estas interacciones muestran la conveniencia de analizar el fenómeno migratorio desde una visión más amplia y no solamente estudiar el comportamiento de los individuos que emigran. Sin duda, al considerar estos factores, es posible tener una visión más completa de 
los impactos y repercusiones de la migración y las remesas en las comunidades expulsoras de mano de obra (Rapoport y Docquier, 2006).

La utilización creciente de modelos con mercados incompletos se ha incorporado también a los estudios que involucran el desarrollo económico. Han surgido nuevas perspectivas que señalan la complejidad de la migración como una institución económica; las interrelaciones entre los determinantes de la migración y sus impactos, así como el papel de los hogares en la toma de decisiones. Por ejemplo, Stark (1991) señaló que los migrantes juegan el papel de intermediarios financieros, lo que permite que los hogares suavicen sus restricciones de riesgo y crédito.

La NELM señala que la mayoría de los migrantes proviene de hogares en situación de pobreza. Esta proposición es pertinente en la presente investigación, ya que en ella se indaga si la migración se traduce, vía el envío de remesas, en un mecanismo para reducir las privaciones que experimentan los hogares de México después de más de dos décadas de la puesta en marcha del TLCAN (Herrera, 2016; Taylor et al., 2008).

Desde esta perspectiva, los hogares envían migrantes como parte de una estrategia para diversificar las fuentes de ingreso. Taylor (1999) argumenta que las remesas ponen en marcha una dinámica de desarrollo mediante la relajación de las restricciones de producción e inversión que enfrentan los hogares. Las remesas pueden ser utilizadas para impulsar la producción mediante el financiamiento de insumos, nuevas tecnologías y actividades productivas. También actúan como un seguro, ya que proporcionan a los hogares un ingreso poco correlacionado con el ingreso local corriente (Yang, 2011; Rapoport y Docquier, 2006).

La NELM conduce a hipótesis específicas acerca de los efectos de las remesas en los hogares de origen de los migrantes. Si las restricciones de crédito y riesgo están vinculadas y la migración ayuda a los hogares a aliviar estas restricciones, entonces la migración y las remesas deben tener un efecto positivo en los ingresos y en distintos indicadores de desarrollo en los hogares de origen de los migrantes. Cuantas más restricciones de liquidez y de mercado tengan los hogares, es mayor el efecto del ingreso marginal de las remesas y, por tanto, también los efectos potenciales que pueden reflejarse en los niveles de pobreza que prevalecen en sus hogares de origen (Adams, 2011; Taylor, 1999).

\section{Desarkollo y hogares RECEPTORES DE REMESAS ANTE LA FIRMA DEL TLCAN}

La migración se ha intensificado debido a los avances en los medios de comunicación y a las políticas de liberalización económica e integración regional que se han llevado a cabo en distintas regiones del mundo desde fines del siglo xx. Actualmen- 
te, la migración internacional se da principalmente de los países de menor a los de mayor desarrollo relativo. Tomando como base los postulados de la NELM, es posible argumentar que la migración se puede concebir como una estrategia en el seno del hogar para alcanzar su supervivencia social, mientras que el impulso a emigrar se puede concebir como una respuesta a los propios cambios al interior del hogar, así como a transformaciones en su entorno (Stark, 1991). Dichos cambios se originan, por ejemplo, por la presencia de menores de edad y jóvenes que requieren mayores y mejores servicios educativos, así como por la presencia de adultos mayores que requieren servicios de salud con mayor frecuencia que el resto de los miembros del hogar. Los cambios en el entorno pueden ser de expulsión, por cambios en las circunstancias del lugar (región) de origen, por ejemplo, agotamiento de los recursos naturales, cambio climático, violencia, existencia de altos índices de desigualdad social y precarización de los niveles de vida; o de atracción de las regiones de destino, por ejemplo, mejores oportunidades de empleo (OIT, 2005), reintegración familiar, mejores servicios educativos y de salud.

El migrante potencial evalúa la posición de su hogar en la región de origen y las ventajas y desventajas de emigrar a cualquier región de destino. Así, las diferencias entre regiones son un incentivo para la migración. Los obstáculos a la emigración pueden ser los intereses creados en la región de origen (propiedad personal, contacto con parientes y conocidos, familiaridad con las costumbres locales) y las restricciones a la inmigración (políticas restrictivas en las regiones de destino) (Massey, 2015).

La migración tiene distintos impactos en los lugares de origen y destino, pero sin duda, el envío de remesas constituye la manifestación más clara de dichos efectos en los lugares de origen. El traslado de trabajadores tiene una serie de consecuencias positivas y negativas. En las positivas, las remesas son identificadas como el beneficio implícito de la migración para los lugares de origen (Campos y Sobarzo, 2014: Yang, 2011); en las negativas, la emigración de los jóvenes y de los más calificados (Albo y Ordaz, 2011).

Un análisis estadístico muestra que, a partir de la entrada en vigor del TLCAN, hubo un fuerte aumento en la migración de trabajadores mexicanos a los Estados Unidos. Este incremento se registró hasta 2007, año a partir del cual se notó una relativa estabilización de la población nacida en México que reside en Estados Unidos: alrededor de 12 millones de personas (Herrera, 2016). A pesar de la estabilización del flujo migratorio, las remesas que México recibe se han mantenido en niveles superiores a los 20 mil millones de dólares desde 2005, alcanzando su máximo nivel en 2016: 26,970 millones de dólares, cifra superior a la que se registró en 2007 (BBVA, 2017).

Asimismo, a partir de 1994, se registró un importante aumento en la inversión extranjera directa; sin embargo, en este año se cambió en México la metodología de cálculo para la IED, por lo que no es posible identificar cuánto de ese aumento se 
debe al cambio en la metodología y cuánto se debe a un aumento real en la IED. Para un análisis detallado de las operaciones financieras que explican parte de las fluctuaciones en los flujos de IED, de las exportaciones de productos petroleros y de los flujos migratorios después de la firma del TLCAN, véase Herrera (2016).

Se ha señalado que las remesas pueden superar en monto a otros rubros macroeconómicos importantes, como a la IED y a las exportaciones (Canales, 2008). Como puede observarse en el cuadro 1, la evolución de la proporción de las remesas en la IED y en las exportaciones, en el periodo 1983-2016, presenta tres fases. En la primera, de 1983 a 1994, las remesas representaron el 73 por ciento de la IED y el 6 por ciento de las exportaciones; las tasas de crecimiento promedio anual de las remesas, la IED y las exportaciones, en ese periodo, fueron 12.0, 6.3 y 9.1 por ciento, respectivamente. En la segunda fase, de 1995 a 2002, las remesas cayeron como proporción de la IED y de las exportaciones, pues representaron solamente el 42 y el 5 por ciento, para cada caso; las tasas de crecimiento promedio anual de las remesas, la IED y las exportaciones, en ese periodo, fueron $8.0,16.3$ y 10.4 por ciento, respectivamente. Sin embargo, en la tercera fase, la proporción promedio de las remesas creció de tal manera que alcanzó a superar los montos registrados de la IED y el 8 por ciento de las exportaciones; las tasas de crecimiento promedio anual de las remesas, la IED y las exportaciones, en el periodo, fueron 5.7, 3.1 y 7.0 por ciento, respectivamente. Estas cifras sugieren que, en el caso de México, las remesas juegan un papel importante en su desarrollo.

Cuadro 1. Remesas como proporción promedio de la inversión extranjera directa (IED) y de las exportaciones. México 1983-2016

\begin{tabular}{|c|c|c|}
\hline PERIODO & REMESAS/ED & REMESAS/EXP. \\
\hline \multirow{2}{*}{$1983-1994$} & 0.73 & 0.06 \\
\cline { 2 - 3 } & $(-0.39)$ & $(-0.01)$ \\
\hline \multirow{2}{*}{$1995-2002$} & 0.42 & 0.05 \\
\cline { 2 - 3 } & $(-0.1)$ & $(-0.01)$ \\
\hline \multirow{2}{*}{$2003-2016$} & 1 & 0.08 \\
\cline { 2 - 3 } & $(-0.47)$ & $(-0.02)$ \\
\hline
\end{tabular}

Fuente: elaboración propia con series del Banco de México (1980 a 1992 y 1993 a 2017).

Existe consenso entre los investigadores del tema acerca de la presencia de una relación positiva entre remesas y desarrollo. Sin embargo, algunos ponen un mayor énfasis en el efecto en el consumo inmediato y otros en el efecto en la acumulación de capital. Lo que sí está claro es que las remesas enviadas a los países de origen constituyen un ingreso real y tangible para los hogares receptores. Como todo ingreso, se puede utilizar en bienes de consumo o de inversión. Entre estos últimos, los 
hogares lo pueden destinar a inversión en capital físico y capital humano. Cualquiera que sea el destino del ingreso por remesas, consumo o inversión (ahorro), existen diversos estudios que muestran evidencia clara de que las remesas promueven el desarrollo en las regiones de origen (Taylor y Castelhano, 2016; Woodruff y Zenteno, 2007; Adams, 2011).

Algunos investigadores concluyen que las remesas se destinan principalmente al consumo diario, con poco impacto directo en las actividades productivas (Pardo y Dávila, 2017; Canales, 2006). Sin embargo, quienes llegan a esta conclusión, al menos teóricamente, ignoran el impacto sobre la actividad económica regional que genera la demanda efectiva en bienes de consumo. Debemos agregar que el gasto en bienes de consumo presiona sobre la capacidad instalada para la producción de dichos bienes y estimula la inversión en nueva capacidad productiva (maquinaria, equipo y trabajo) para satisfacer los requerimientos de producción de dichos bienes (principio de aceleración, Samuelson, 1939).

Otros investigadores concluyen que las remesas aumentan las inversiones en capital físico y humano (Mora y Arellano, 2016). El primero aumenta directamente la capacidad productiva y el crecimiento económico, mientras que el segundo afecta positivamente el crecimiento económico por medio del incremento en las competencias laborales y, por lo tanto, en el aumento de la productividad del trabajo. En este sentido, la escolaridad debe considerarse como una inversión productiva rentable, aunque tenga un largo periodo de gestación; también los gastos en vivienda, los cuales estimulan las actividades de construcción (Adams et al., 2008). En una revisión de los estudios llevados a cabo en México, Durand y Massey (1992) encontraron que el porcentaje de las remesas dedicado a actividades productivas fluctuó de un lugar a otro y siempre estuvo por debajo del 50 por ciento. Las remesas permitieron que las comunidades receptoras financiaran proyectos de obras públicas como parques, iglesias, escuelas, electrificación, construcción de carreteras y drenaje (Massey et al., 1987). Otros estudios señalan que las remesas han sido importantes para la capitalización de empresas que pertenecían a migrantes (Woodruff y Zenteno, 2007). Por ejemplo, Escobar y Martínez (1990) encontraron que 31 por ciento de los migrantes encuestados en Guadalajara utilizó lo ahorrado, gracias a las remesas, para la creación de empresas. En la encuesta realizada por Massey et al. (1987), en la misma ciudad, la cifra alcanza 21 por ciento. En un estudio sobre empresas ubicadas en tres comunidades rurales de México, Cornelius (1990) encontró que 61 por ciento de éstas habían sido fundadas con ingresos provenientes de remesas. Una serie de estudios realizados en otras regiones del mundo hacen eco de estos resultados (para un análisis detallado, ver Adams, 2011 y Taylor y Castelhano, 2016).

Mora y Arellano (2016) concluyeron que una comparación del gasto de los hogares con y sin remesas revela que el primer grupo gasta una mayor proporción 
en salud, en bienes duraderos y en patrimonio; que las remesas externas afectan positivamente las inversiones de capital físico y que tienen un efecto benéfico en el gasto en salud, aunque no tuvieron un efecto significativo en el gasto en educación. En particular, la propensión a gastar en algunas categorías de inversión (educación, salud, bienes duraderos y patrimonio) parece ser considerablemente mayor en el caso de los hogares que reciben remesas, internas o externas, en comparación con los hogares que no las reciben.

Cuadro 2. Distribución promedio del gasto de los hogares por condición de recepción de remesas (\%) en México 2010, 2012 y 2014

\begin{tabular}{|l|c|c|c|}
\hline \multicolumn{1}{|c|}{ TIPO DE GASTO } & REMESAS INTERNACIONALES & REMESAS NACIONALES & NO RECIBE REMESAS \\
\hline Alimentación & 38.5 & 37.2 & 33.6 \\
\hline Educación básica & 3.2 & 5.1 & 4.3 \\
\hline Educación superior & 2.9 & 4.8 & 3.8 \\
\hline Salud & 6.3 & 4.2 & 3.7 \\
\hline Bienes de consumo no duradero & 11.8 & 12.5 & 13.1 \\
\hline Bienes de consumo duradero & 1.5 & 1.3 & 1.3 \\
\hline Otros & 18.9 & 18.7 & 18.2 \\
\hline Patrimonio & 4.9 & 5.4 & 5.2 \\
\hline Negocios & 0.3 & 0.1 & 0.2 \\
\hline Ahorro & 11.7 & 10.7 & 16.6 \\
\hline
\end{tabular}

Fuente: elaboración propia con base en los microdatos de la ENIGH 2010, 2012 y 2014.

Con cifras recientes, los resultados del cuadro 2 apoyan la afirmación de Mora y Arellano (2016): los hogares receptores de remesas externas tienen una mayor proporción de gasto en salud, bienes de consumo duradero y negocios que los hogares receptores de remesas internas y hogares no receptores de remesas. Pero no apoyan la afirmación de que gastan más en patrimonio. En síntesis, podemos concluir que existe un efecto positivo de las remesas del exterior en el desarrollo de las regiones de origen.

Es importante señalar que a pesar de que la migración puede ser un instrumento de desarrollo para los países de origen, también puede crear efectos adversos a dicho desarrollo. 1) Un posible efecto adverso se generaría si la emigración de trabajadores fuera tal que ocasionara que el mercado laboral, caracterizado por la presencia de desempleo y subempleo, pasara a ser un mercado de escasez laboral. Esta situación de escasez originaría una presión al alza de los salarios en el país de origen, lo cual produciría presión inflacionaria con sus consecuentes problemas redistributivos y de asignación de recursos (Pellegrino, 2003; OIT, 2005). 2) Otro posible factor adverso tendría su origen en el hecho de que los jóvenes son más propensos a emigrar, ya sea porque asumen mayores riesgos y cuentan con mejores 
oportunidades de encontrar empleo en las sociedades de destino (McKenzie, 2008), o porque tienen menos intereses creados en los lugares de origen. Este hecho podría afectar negativamente las posibilidades de desarrollo de los países de origen (Pellegrino, 2003). 3) Finalmente, el país de origen puede terminar subsidiando con su inversión en capital humano (escolaridad) a un país de destino, desarrollado, vía la emigración del trabajo más escolarizado. La decisión de emigrar de los miembros más educados del hogar implica una pérdida en inversión en capital humano de las regiones de origen con impactos y costos importantes para su desarrollo de largo plazo (PNUD, 2007). Así, se agrava la brecha existente entre los niveles de escolaridad y los de habilidades productivas en las regiones de destino y las regiones de origen, lo que refuerza las condiciones para la migración (Durand y Massey, 1992). De esta forma, la recepción de remesas en los hogares y regiones de origen tiene como contrapartida la pérdida de capital humano, ya que, generalmente, son los miembros más escolarizados los que emigran (Albo y Ordaz, 2011; PNUD, 2007). Estos efectos adversos pueden revertirse, al menos parcialmente, con la migración de retorno, ya que sus miembros han adquirido competencias laborales adicionales, que les pueden dar un mejor manejo de los recursos disponibles en su región de origen.

En la siguiente sección presentamos información estadística y algunos cálculos de distintos indicadores de bienestar y desarrollo para hogares inmersos y ajenos al fenómeno migratorio que permiten contribuir al debate sobre los efectos (positivos y adversos) que la dinámica del propio fenómeno origina en los lugares y hogares de origen.

\section{DATOS Y DISEÑO DE LA INVESTIGACIÓN}

En esta sección se describen las bases de datos utilizadas en la presente investigación, así como la ruta metodológica aplicada en el análisis estadístico de la evolución de las características de pobreza presentes en los hogares receptores y no receptores de remesas.

\section{III.1. Datos y unidad de análisis}

Los datos utilizados para el presente artículo provienen del Módulo de Condiciones Socioeconómicas ${ }^{2}$ (MCS) de la Encuesta Nacional de Ingresos y Gastos de los Hogares (ENIGH) en los años 2010, 2012 y 2014, más una base subsecuente de pobreza

${ }^{2} \mathrm{El}$ MCS fue creado para proporcionar un panorama estadístico de las variables necesarias para la medición multidimensional de la pobreza, establecidas en la Ley General de Desarrollo Social (MCS, 2014) 
multidimensional, cuya metodología fue propuesta por el Consejo Nacional de Evaluación de la Política de Desarrollo Social (CONEval) a partir de la información del MCS. ${ }^{3}$ Mientras que la entrada en vigor del TLCAN fue en 1994, la medición multidimensional de la pobreza se definió oficialmente en 2004 y fue hasta 2008 que aparece la primera medición oficial de la pobreza multidimensional presentada por el coNEVAL, lo que limita la temporalidad de análisis de los indicadores de pobreza antes y después del TLCAN.

En México, diversos estudios que investigan el papel de las remesas utilizan la ENIGH, tal es el caso de Mora y Arellano (2016), Pardo y Dávila (2017) y Canales (2006); sin embargo, en este análisis se considera pertinente la utilización del MCS por dos ventajas respecto a la ENIGH. La primera ventaja está relacionada con la representatividad de la información: mientras que la ENIGH es representativa a nivel nacional, rural y urbano, el MCS lo es también a nivel estatal, lo cual permite mayor precisión en la información y posibilita futuras comparaciones entre los estados de la república. La segunda ventaja está vinculada directamente con el propósito de este documento, ya que, a diferencia de la ENIGH, el MCS posibilita el análisis de la pobreza multidimensional en los grupos de hogares de nuestro interés; es decir, el módulo permite el análisis de la pobreza en cada una de sus dimensiones, y aunque la base de datos no está diseñada para analizar el fenómeno migratorio, también nos permite identificar a los hogares receptores de remesas que son parte fundamental del objetivo central de este artículo.

En este estudio, la unidad de análisis son los hogares que reciben remesas. A partir de ello se analiza el comportamiento y la evolución de los indicadores de pobreza multidimensional en los hogares que reciben remesas internas (nacionales) y externas (internacionales), así como en los que no reciben. ${ }^{4}$

\section{III.2. Características sociodemográficas de los hogares} receptores de remesas

A partir de la base de datos generada para este artículo se encontró que en 2010 el 81.3 por ciento de los hogares nacionales no recibía algún tipo de remesa o transferencia monetaria, el 15.3 por ciento recibía remesas de tipo nacional y el 3.3 por ciento, remesas internacionales. Para 2012, el 80 por ciento de los hogares no recibía remesas, el 17 por ciento recibía remesas nacionales y el 3 por ciento, remesas internacionales.

${ }^{3}$ Son una serie de carencias definidas en múltiples dominios (CONEVAL, 2010).

${ }^{4}$ Las remesas nacionales se consideran como el "dinero proveniente de otros hogares", mientras que las remesas internacionales se pueden identificar en el MCs como "ingresos procedentes de otros países". Para más detalle, véase Mora y Arellano (2016). 
En 2014, el comportamiento fue más similar a 2010 que a 2012. El 82 por ciento de los hogares no recibía remesas de ningún tipo, el 15 por ciento recibía remesas nacionales y, nuevamente, el 3 por ciento de los hogares recibía remesas internacionales. Los porcentajes anteriores son consistentes con las cifras presentadas en trabajos previos, como los de Canales (2006) y Pardo y Dávila (2017), en los que se hace especial énfasis en el bajo número de hogares receptores de remesas internacionales.

Las características sociodemográficas de los hogares que se analizan en el estudio muestran ciertas disparidades y similitudes. En el cuadro 3 se muestran las variables de interés del jefe de hogar en los años de estudio (2010, 2012 y 2014) y la condición de recepción de remesas para cada grupo de hogares analizados.

Los datos del cuadro 3 muestran que, en los tres años de análisis, la jefatura del hogar es predominantemente masculina, los hogares no receptores de remesas presentan las mayores cifras, incluso mayores que el promedio nacional; sin embargo, la proporción de hogares con jefe de familia mujer es mayor en los hogares que reciben remesas internacionales, alrededor del 42 por ciento. En años anteriores la migración era considerada como un fenómeno principalmente masculino. Sin embargo, en los últimos años la brecha entre las tasas migratorias de mujeres y hombres ha disminuido considerablemente. Diversos estudios encuentran que en años recientes no existe diferencia en la migración entre hombres y mujeres (Bastia, 2009; Loza et al., 2007). Ahora bien, a pesar del crecimiento importante de la migración femenina, al observar la cantidad de hogares receptores con jefatura femenina, se puede intuir que la propensión a migrar de los hombres sigue siendo mayor en términos absolutos, lo que implicaría que en su mayoría las mujeres permanecen en los lugares de origen, convirtiéndose en las jefas de familia.

Para cada uno de los grupos de hogares se observa que la mayor parte de los jefes son casados, ${ }^{5}$ con proporciones mayores al 60 por ciento (cuadro 3 ). No obstante las cifras, los hogares receptores de remesas internacionales son los que registran mayores proporciones en 2010 y 2012, disminuyendo considerablemente en 2014, año donde fueron superados por los hogares no receptores. Respecto a escolaridad, se observa que los jefes de hogares que reciben remesas del extranjero tienen menores niveles de escolaridad que el resto de los otros grupos. Por ejemplo, sumando nivel profesional y posgrado, los jefes de hogares que reciben remesas internacionales no llegan a sumar el 8 por ciento en estos niveles educativos; en cambio, en los hogares no receptores, los jefes con estos niveles educativos llegan a representar más del 20 por ciento, cifra un poco menor para los jefes de hogares con remesas

${ }^{5}$ La variable "casado" se construyó a partir del estado conyugal reportado en el MCS. Se tomó como casados a aquellos que contestaron que tenían un matrimonio o vivían en unión libre. Soltero corresponde a todos los demás. 
nacionales (alrededor del 18 por ciento). Este comportamiento se mantiene durante los tres años del periodo de análisis. Estos datos son consistentes con lo que otras investigaciones sobre migración han señalado. En primer lugar, muestran que los niveles educativos asociados a los migrantes internacionales son menores que los registrados por los migrantes nacionales (Mora y Taylor, 2006), resultado probablemente asociado a los mayores rendimientos de la educación en el mercado laboral nacional (Retamoza y Alonso, 2014; Yúnez y Taylor, 2001). En segundo lugar, indican que a pesar del crecimiento de los niveles de escolaridad de las nuevas generaciones de migrantes internacionales, en los promedios nacionales dicho segmento de la población aún permanece subrepresentado, lo cual indica que el fenómeno de la fuga de cerebros quizá aún es bajo aunque ha crecido en la última década, justo como lo indican algunas investigaciones en el tema (Tuirán y Ávila, 2013; Albo y Ordaz, 2011). En tercer lugar, señala que en términos de la migración interna es posible postular un cambio de patrón migratorio entre las entidades del país con más presencia de trabajadores con mayor nivel educativo (García y Garro, 2016).

Las mayores proporciones de jefes de hogar se encuentran en edades productivas, entre los 30 y 49 años. En los hogares no receptores, la proporción en este intervalo de edad es aproximadamente del 50 por ciento, mientras que en los dos tipos de hogares receptores, un poco más de un tercio de los jefes de hogar se encuentra en dicho intervalo de edades. Es notorio que los jefes de hogar clasificados como adultos mayores se ubican en mayor proporción en los hogares receptores; por ejemplo, en 2014, poco más del 25 por ciento de los jefes de los hogares que reciben remesas se encontraba en esta clasificación, siendo considerablemente menor el porcentaje de jefes de familia en hogares no receptores que estaba en este rango de edad (13.5 por ciento). Quizá esta característica de los hogares receptores se atribuya a la capacidad que tienen los migrantes de ser altruistas con los miembros del hogar que permanecen en los lugares de origen, justo como lo mencionan algunas de las vertientes teóricas que explican los motivos para el envío de las remesas (Rapoport y Docquier, 2006). Otra posible explicación, ligada a la anterior, es la existencia de reciprocidad diferida entre los migrantes y sus padres, situación a través de la cual los migrantes (hijos) ayudan en el sostenimiento económico de sus padres por medio del envío de remesas, ya sea para los gastos necesarios en el consumo diario o para afrontar los mayores costos de salud asociados en mayor medida a los adultos mayores (Canales, 2005).

En relación con la presencia de jefes de hogar indígena, no es posible detectar diferencias notorias entre los grupos de hogares de nuestro análisis. Prácticamente en los tres años de estudio y en los tres grupos de hogares, la proporción de jefes indígenas se encontraba cercana al 7 por ciento. A pesar del incremento en la migración indígena, este resultado está asociado al mayor grado de marginación y 
pobreza en que viven este tipo de hogares, lo que hace más difícil que puedan afrontar los altos costos asociados con la migración, especialmente la internacional (Lira et al., 2016).

Por último, podemos señalar que, en el total de hogares mexicanos, la mayor parte de los jefes se encuentran en zonas urbanas ( 80 por ciento), el resto vive en regiones rurales. Este comportamiento del promedio nacional es similar al registrado en los hogares que reciben remesas nacionales y en aquellos hogares en que no ocurre así. Sin embargo, la proporción que se registra en los hogares receptores de remesas internacionales es muy distinta. Por ejemplo, en 2014 más de la mitad de los jefes de hogar con remesas internacionales vivía en localidades rurales, lo que señala que el fenómeno migratorio sigue siendo en mayor proporción un fenómeno característico del sector rural mexicano, justo como lo mencionan estudios previos que abordan la migración internacional mexicana (Durand, 2016).

Cuadro 3. Estadísticas de interés de los jefes de hogar por condición de recepción de remesas y total nacional en México 2010, 2012 y 2014

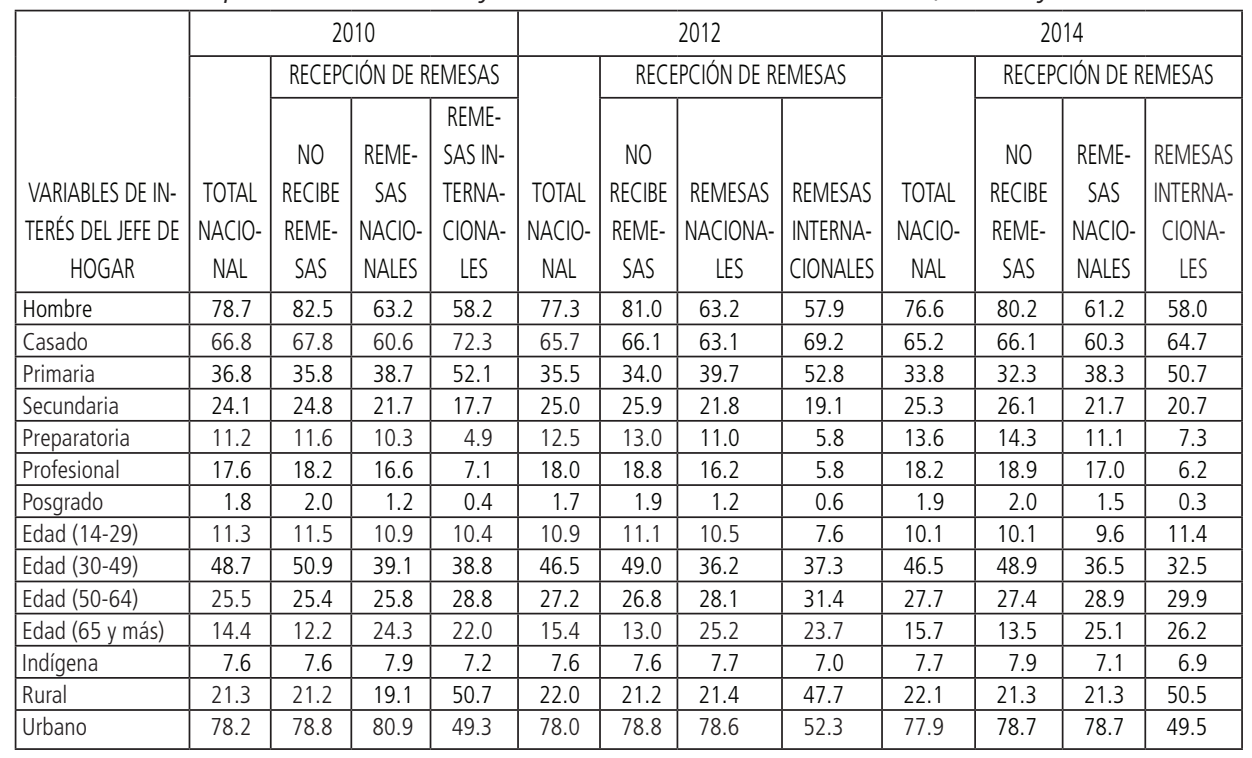

Fuente: elaboración propia con datos del Mcs, 2010, 2012 y 2014. Las cifras están en porcentajes.

\section{III.3. Hogares receptores de remesas y pobreza multidimensional}

En este apartado se presenta un análisis en dos etapas de los indicadores de la pobreza multidimensional para los hogares receptores y no receptores de remesas. En 
la primera se hace una descripción del comportamiento de los niveles de pobreza en los grupos de hogares de interés en un plano nacional, mientras que en la segunda etapa, se presenta evidencia del comportamiento de los indicadores de pobreza haciendo distinción, además de la condición de recepción de remesas, entre los hogares rurales y urbanos. ${ }^{6}$

Con respecto a los indicadores de pobreza, se tomaron los propuestos por el CONEVAL, los cuales reflejan la medición oficial actual de la pobreza en México. La metodología multidimensional de medición de la pobreza considera los siguientes ocho indicadores: 1) Ingreso per cápita; 2) Rezago educativo promedio en el hogar; 3) Acceso a los servicios de salud; 4) Acceso a la seguridad social; 5) Calidad y espacios de la vivienda; 6) Acceso a los servicios básicos de la vivienda; 7) Acceso a la alimentación y 8) Grado de cohesión social. ${ }^{7}$ A la fecha se han realizado cuatro mediciones con la metodología multidimensional: 2008, 2010, 2012 y 2014. Con el fin de que la información sea homogénea y comparable en el periodo analizado, en el presente estudio sólo se analizan los últimos tres años, ya que en la medición realizada en 2008 no se consideró el combustible y ello imposibilita su comparación con el resto de las mediciones (CONEVAL, 2010a).

Como se muestra en el cuadro 4, los cálculos indican que en el total nacional de los hogares, los niveles de pobreza son similares a los reportados por el CONEvAL; a saber, una disminución de la pobreza en 2012 y un incremento de ésta para el año 2014, llegando nuevamente al porcentaje de hogares pobres registrado en 2010. En cambio, la evolución de la pobreza en los hogares que reciben remesas nacionales e internacionales es contrastante. Aquellos hogares que recibieron remesas nacionales presentan un incremento considerable en la pobreza tanto en 2012 como en 2014, el porcentaje de hogares pobres en este grupo se incrementó en 4.4 por ciento de 2010 a 2014. Este comportamiento podría estar relacionado con el poco dinamismo de la economía mexicana y el escaso crecimiento en las oportunidades laborales en el interior del país; asimismo, es un reflejo de la precarización de los salarios que se ha padecido en los últimos años en México; condiciones que en buena medida reflejan el fracaso de las expectativas generadas con la firma del TLCAN, tal y como lo señalan algunas investigaciones recientes (Herrera, 2016).

${ }^{6}$ Para identificar a los hogares rurales se utilizó el tamaño de localidad y el concepto propuesto por CONEVAL de considerar rural todas aquellas localidades con menos de 2, 500 habitantes (Glosario del CONEval consultado en http:/www.coneval.org.mx/Medicion/Paginas/Glosario.aspx, julio 2017).

${ }^{7}$ Para más información consultar la Ley General de Desarrollo Social en http://www.diputados. gob.mx/LeyesBiblio/pdf/264_010616.pdf, 
Por su parte, la evolución de los niveles de pobreza en los hogares receptores de remesas internacionales ha sido a la baja, mostrando una disminución del 3 por ciento en el número de hogares pobres entre 2010 y 2014. Este hallazgo es consistente con investigaciones que señalan que las remesas contribuyen de manera positiva en la disminución de la pobreza (Taylor et al., 2008; García-Zarate, 2015) y contrasta con estudios que señalan lo opuesto (Canales, 2006). Del mismo modo, estas cifras podrían apoyar la idea de que uno de los efectos "positivos" del TLCAN fue el incremento en el envío de remesas originado por la exportación de mano de obra barata hacia nuestro vecino país del norte, válvula de escape que ha servido por varias décadas a la situación económica prevaleciente en México, pero como enfatizan algunos autores, ha llegado a su límite y difícilmente podrá seguir perpetuándose (Cypher y Delgado-Wise, 2012; Cordera, 2015).

$\mathrm{El}$ incremento en las remesas internacionales y su posible impacto en la reducción de la pobreza permite considerarlas como un instrumento o motor del desarro1lo. Así, las remesas internacionales tendrían un efecto multiplicador que mejoraría las condiciones de ingresos de los hogares de los migrantes, lo que posibilita y potencia la capacidad de compra de bienes que les permite alejarse de los niveles de pobreza (Márquez, 2007).

Respecto a los otros indicadores, es posible señalar que la pobreza moderada se incrementó a nivel nacional en los hogares que no reciben remesas y en los hogares que reciben remesas nacionales; en cuanto a los hogares que reciben remesas internacionales, hubo una disminución del 1.4 por ciento. Por su parte, la pobreza extrema disminuyó para todos los grupos de hogares analizados.

En general, los hogares que no reciben remesas presentan un menor nivel de pobreza y de carencias respecto a los hogares receptores. El único indicador en el que se encuentran mejor los hogares que reciben remesas internacionales respecto a los demás grupos de hogares es el de carencia por calidad y espacios en la vivienda, ya que este tipo de hogares registró, de 2010 a 2014, una disminución de 5.3 por ciento en el número de hogares que padecen dicha carencia.

Si bien el análisis de las cifras presentadas nos invita a pensar que las remesas son un factor que apoya en la mejora de la pobreza, la responsabilidad de mejorar los indicadores de bienestar del país no debería recaer en este tipo de recursos provenientes del exterior y con un grado de incertidumbre alto, sobre todo por la llegada de la nueva administración de nuestro país vecino. El hecho de que a pesar de recibir transferencias de otros hogares dentro del país algunos hogares no puedan mejorar su situación de pobreza, muestra el terrible panorama en el que se encuentran. 
Cuadro 4. Hogares por condición de recepción de remesas y por indicador de pobreza en México 2010, 2012 y 2014

\begin{tabular}{|l|c|c|c|c|c|c|c|c|c|c|c|c|}
\hline \multirow{2}{*}{ POBREZA } & \multicolumn{3}{|c|}{ TOTAL NACIONAL } & \multicolumn{3}{c|}{ NO RECIBE REMESAS } & \multicolumn{3}{|c|}{ REMESAS NACIONALES } & \multicolumn{3}{|c|}{ REMESAS INTERNACIONALES } \\
\cline { 2 - 13 } & 2010 & 2012 & 2014 & 2010 & 2012 & 2014 & 2010 & 2012 & 2014 & 2010 & 2012 & 2014 \\
\hline $\begin{array}{l}\text { Población en situación } \\
\text { de pobreza }\end{array}$ & 43.1 & 42.6 & 43.0 & 42.8 & 42.0 & 42.1 & 42.1 & 44.1 & 46.5 & 52.2 & 49.8 & 49.2 \\
\hline $\begin{array}{l}\text { Población en situación } \\
\text { de pobreza moderada }\end{array}$ & 32.9 & 33.4 & 34.2 & 32.6 & 32.8 & 33.4 & 32.8 & 34.7 & 37.6 & 41.4 & 40.1 & 39.0 \\
\hline $\begin{array}{l}\text { Población en situación } \\
\text { de pobreza extrema }\end{array}$ & 10.2 & 9.2 & 8.8 & 10.2 & 9.2 & 8.7 & 9.34 & 9.32 & 8.90 & 10.7 & 9.7 & 10.1 \\
\hline Rezago educativo & 28.5 & 27.7 & 26.7 & 26.4 & 25.4 & 24.6 & 34.2 & 34.4 & 33.4 & 52.7 & 50.9 & 50.6 \\
\hline $\begin{array}{l}\text { Carencia por acceso a } \\
\text { los servicios de salud }\end{array}$ & 26.2 & 18.8 & 15.7 & 25.9 & 18.8 & 15.4 & 26.2 & 18.4 & 16.4 & 32.2 & 23.2 & 21.2 \\
\hline $\begin{array}{l}\text { Carencia por acceso a } \\
\text { la seguridad social }\end{array}$ & 56.8 & 56.5 & 53.2 & 56.5 & 56.7 & 53.2 & 54.0 & 52.9 & 51.2 & 74.3 & 70.6 & 65.2 \\
\hline $\begin{array}{l}\text { Carencia por calidad y } \\
\text { espacios en la vivienda }\end{array}$ & 12.5 & 11.4 & 10.0 & 12.9 & 11.7 & 10.2 & 10.4 & 10.2 & 9.2 & 13.3 & 8.8 & 8.0 \\
\hline $\begin{array}{l}\text { Carencia por acceso a } \\
\text { los servicios básicos en } \\
\text { la vivienda }\end{array}$ & 21.0 & 19.8 & 19.7 & 20.9 & 19.5 & 19.3 & 18.4 & 19.7 & 19.4 & 35.4 & 29.6 & 31.6 \\
\hline $\begin{array}{l}\text { Carencia por acceso a } \\
\text { la alimentación }\end{array}$ & 22.3 & 21.6 & 21.6 & 21.5 & 20.9 & 20.9 & 26.1 & 24.4 & 24.9 & 23.6 & 22.7 & 25.0 \\
\hline
\end{tabular}

Fuente: elaboración propia con datos del MCS y el CONEVAL, 2010, 2012 y 2014. Las cifras están en porcentajes.

Como se puede ver en los cuadros 5 y 6 , el comportamiento nacional del hogar pobre varía según el sector rural o urbano. Por ejemplo, en 2014, en el sector rural la cantidad de hogares en situación de pobreza fue 20 por ciento mayor que en el urbano y, a diferencia del comportamiento nacional, la pobreza rural disminuyó en 2.7 puntos porcentuales de 2010 a 2014. Todos los hogares que no reciben remesas, como los que sí, han presentado el mismo comportamiento: una disminución en la pobreza en los tres años de análisis.

A pesar de que la pobreza ha disminuido, la pobreza moderada no ha tenido el mismo comportamiento, presentando un incremento de 2010 a 2014 en el total nacional ( 1 por ciento), en los hogares que no reciben remesas ( 0.9 por ciento) y en los hogares que reciben remesas nacionales ( 2.4 por ciento), y sólo presentó una ligera disminución en aquellos hogares que reciben remesas del extranjero.

Respecto al rezago educativo, existe una notable diferencia entre aquellos hogares que no reciben remesas y los que reciben remesas de tipo nacional e internacional. En 2014, los hogares que reciben remesas nacionales presentan un rezago educativo 7.9 por ciento mayor que los hogares que no reciben remesas. Y los que 
reciben remesas internacionales presentan un rezago 17.1 por ciento mayor en la intensidad de esta carencia con respecto a los hogares que no reciben remesas. En la carencia por calidad y espacios de la vivienda también ha habido una disminución en todos los grupos de hogares, mostrando una disminución mayor en los hogares que reciben remesas internacionales.

A partir de la entrada en vigor del TLCAN se esperaba que incrementara la emigración mexicana en el ámbito rural, que la agricultura fuera afectada negativamente, y que los efectos positivos se observaran en los otros sectores de la economía. La información obtenida permite afirmar que son los hogares rurales los que presentaron un mayor movimiento migratorio, aunque no es posible con la información disponible evaluar las implicaciones positivas y negativas, y de causa y efecto, de ese hecho. Por un lado, la migración afecta al sector agrícola, pero la situación precaria del país también lo hace, porque su incapacidad de generar empleos bien remunerados también incrementa la emigración. Por el otro lado, la emigración genera remesas que han mejorado la situación de los hogares rurales y que se ha contrastado con la situación de los hogares no receptores de remesas (Herrera, 2016).

Cuadro 5. Hogares rurales por condición de recepción de remesas y por indicador de pobreza en México 2010, 2012 y 2014

\begin{tabular}{|l|c|c|c|c|c|c|c|c|c|c|c|c|}
\hline \multirow{2}{*}{ POBREZA } & \multicolumn{3}{|c|}{ TOTAL NACIONAL } & \multicolumn{3}{c|}{ NO RECIBE REMESAS } & \multicolumn{2}{c|}{ REMESAS NACIONALES } & \multicolumn{3}{|c|}{ REMESAS INTERNACIONALES } \\
\cline { 2 - 13 } & 2010 & 2012 & 2014 & 2010 & 2012 & 2014 & 2010 & 2012 & 2014 & 2010 & 2012 & 2014 \\
\hline $\begin{array}{l}\text { Población en situación } \\
\text { de pobreza }\end{array}$ & 62.1 & 59.5 & 58.7 & 62.8 & 59.9 & 58.8 & 62.0 & 60.3 & 59.7 & 56.1 & 51.2 & 53.3 \\
\hline $\begin{array}{l}\text { Población en situación } \\
\text { de pobreza moderada }\end{array}$ & 37.6 & 38.3 & 38.6 & 37.0 & 37.9 & 37.9 & 39.0 & 40.3 & 41.4 & 40.5 & 37.4 & 40.1 \\
\hline $\begin{array}{l}\text { Población en situación } \\
\text { de pobreza extrema }\end{array}$ & 24.6 & 21.2 & 20.1 & 25.7 & 22.1 & 20.9 & 22.9 & 20.0 & 18.3 & 15.6 & 13.8 & 13.1 \\
\hline Rezago educativo & 52.2 & 51.1 & 49.7 & 49.4 & 48.0 & 47.4 & 60.6 & 60.1 & 55.3 & 67.0 & 65.1 & 64.5 \\
\hline $\begin{array}{l}\text { Carencia por acceso a } \\
\text { los servicios de salud }\end{array}$ & 29.8 & 18.5 & 15.3 & 29.5 & 18.4 & 15.1 & 31.3 & 18.0 & 14.6 & 30.2 & 20.8 & 18.2 \\
\hline $\begin{array}{l}\text { Carencia por acceso a la } \\
\text { seguridad social }\end{array}$ & 77.2 & 76.1 & 73.3 & 77.9 & 77.0 & 74.4 & 71.3 & 71.4 & 67.9 & 79.9 & 77.7 & 71.7 \\
\hline $\begin{array}{l}\text { Carencia por calidad y } \\
\text { espacios en la vivienda }\end{array}$ & 25.4 & 20.1 & 18.2 & 26.7 & 21.4 & 19.4 & 22.5 & 17.3 & 16.2 & 16.9 & 11.9 & 8.1 \\
\hline $\begin{array}{l}\text { Carencia por acceso a } \\
\text { los servicios básicos en } \\
\text { la vivienda }\end{array}$ & 61.3 & 56.3 & 56.3 & 61.8 & 56.8 & 57.0 & 60.8 & 56.5 & 55.3 & 57.6 & 49.4 & 50.4 \\
\hline $\begin{array}{l}\text { Carencia por acceso a la } \\
\text { alimentación }\end{array}$ & 31.3 & 29.5 & 30.5 & 31.4 & 29.9 & 30.1 & 33.8 & 29.9 & 34.1 & 26.5 & 23.8 & 27.9 \\
\hline
\end{tabular}

Fuente: elaboración propia con datos del MCs y el CONEVAL, 2010, 2012 y 2014. Las cifras están en porcentajes. 
Por su parte, los hogares que viven en localidades urbanas presentan niveles de pobreza menores a los registrados en los hogares rurales. La diferencia nacional entre los hogares rurales y urbanos fue de 20 puntos porcentuales en 2014, lo que permite vislumbrar parcialmente el panorama de desigualdad en el que se encuentra el país.

De 2010 a 2014, la pobreza aumentó en los hogares urbanos. En aquellos hogares que no reciben remesas el cambio fue mínimo. Sin embargo, los hogares que reciben remesas nacionales tuvieron un incremento en su nivel de pobreza de 5.5 por ciento. A diferencia de éstos, los hogares con remesas internacionales disminuyeron su pobreza en 3.2 por ciento.

La pobreza moderada tiene el mismo comportamiento que la pobreza, mientras que la pobreza extrema presenta una disminución en los hogares que no reciben remesas y un incremento en los hogares que reciben algún tipo de remesa. En rezago educativo, tanto los que reciben remesas como los que no reciben tienen una disminución en sus indicadores de al menos 1.5 por ciento; la carencia por acceso a los servicios de salud también disminuyó en los tres años de análisis.

Cuadro 6. Hogares urbanos por condición de recepción de remesas y por indicador de pobreza en México 2010, 2012 y 2014

\begin{tabular}{|l|r|r|r|r|r|r|r|r|r|r|r|r|}
\hline \multirow{2}{*}{ POBREZA } & \multicolumn{3}{|c|}{ TOTAL NACIONAL } & \multicolumn{2}{c|}{ NO RECIBE REMESAS } & \multicolumn{2}{c|}{ REMESAS NACIONALES } & \multicolumn{3}{c|}{ REMESAS INTERNACIONALES } \\
\cline { 2 - 15 } & 2010 & 2012 & 2014 & 2010 & 2012 & 2014 & 2010 & 2012 & 2014 & 2010 & 2012 & 2014 \\
\hline $\begin{array}{l}\text { Población en situación } \\
\text { de pobreza }\end{array}$ & 37.6 & 37.8 & 38.7 & 37.4 & 37.2 & 37.6 & 37.5 & 39.6 & 43.0 & 48.1 & 48.6 & 44.9 \\
\hline $\begin{array}{l}\text { Población en situación } \\
\text { de pobreza moderada }\end{array}$ & 31.6 & 32.0 & 33.1 & 31.4 & 31.5 & 32.2 & 31.3 & 33.2 & 36.6 & 42.4 & 42.6 & 37.9 \\
\hline $\begin{array}{l}\text { Población en situación } \\
\text { de pobreza extrema }\end{array}$ & 6.1 & 5.8 & 5.6 & 6.0 & 5.7 & 5.4 & 6.14 & 6.41 & 6.36 & 5.7 & 6.0 & 7.0 \\
\hline Rezago educativo & 21.8 & 21.1 & 20.1 & 20.2 & 19.3 & 18.4 & 28.0 & 27.4 & 27.4 & 38.0 & 38.0 & 36.5 \\
\hline $\begin{array}{l}\text { Carencia por acceso a } \\
\text { los servicios de salud }\end{array}$ & 25.2 & 18.9 & 15.9 & 25.0 & 18.9 & 15.4 & 25.0 & 18.5 & 16.9 & 34.3 & 25.5 & 24.4 \\
\hline $\begin{array}{l}\text { Carencia por acceso a la } \\
\text { seguridad social }\end{array}$ & 51.0 & 50.9 & 47.6 & 50.8 & 51.3 & 47.5 & 50.0 & 47.8 & 46.7 & 68.5 & 64.1 & 58.5 \\
\hline $\begin{array}{l}\text { Carencia por calidad y } \\
\text { espacios en la vivienda }\end{array}$ & 8.9 & 8.9 & 7.6 & 9.2 & 9.1 & 7.7 & 7.5 & 8.3 & 7.3 & 9.6 & 6.1 & 7.8 \\
\hline $\begin{array}{l}\text { Carencia por acceso a } \\
\text { los servicios básicos en } \\
\text { la vivienda }\end{array}$ & 9.8 & 9.5 & 9.3 & 9.9 & 9.5 & 9.1 & 8.4 & 9.6 & 9.7 & 12.6 & 11.5 & 12.4 \\
\hline $\begin{array}{l}\text { Carencia por acceso a la } \\
\text { alimentación }\end{array}$ & 19.7 & 19.3 & 19.1 & 18.8 & 18.5 & 18.4 & 24.3 & 22.9 & 22.4 & 20.6 & 21.7 & 22.0 \\
\hline
\end{tabular}

Fuente: elaboración propia con datos del MCS y el cONEVAL, 2010, 2012 y 2014. Las cifras están en porcentajes. 


\section{III.4. Hogares receptores de remesas y pobreza multidimensional por decil de ingreso}

En el apartado anterior se identificó el comportamiento de los hogares receptores y no receptores de remesas según los niveles de pobreza y varios de sus indicadores. En esta sección se agrupan los hogares por decil según el ingreso corriente total del hogar. ${ }^{8}$ Para construir el ingreso corriente monetario se utilizan los rubros que define el ingreso. Es decir, se suma el valor del autoconsumo, las remuneraciones en especie, las transferencias en especie de otros hogares y las estimaciones de alquiler de la vivienda. Al final se le restan los regalos dados por el hogar (CONEVAL, 2009).

En el cuadro 7 se muestra la distribución de los hogares por decil de ingreso que reciben remesas, nacionales e internacionales, así como los hogares que no las reciben. Se destaca una distribución más homogénea en los hogares que no reciben remesas; la diferencia entre los deciles no es mayor al 1.2 por ciento en cada uno de los años analizados. Los deciles 6, 7, 8 y 9 tienen los menores porcentajes de hogares, mientras que los primeros tres deciles y el décimo tienen los mayores porcentajes.

En los tres años analizados, se muestra una tendencia decreciente en la distribución porcentual de los hogares que reciben remesas nacionales a medida que se asciende en la escala; es decir, en los deciles de menor ingreso se concentran los hogares receptores de remesas nacionales. Además, se observa un incremento en la brecha entre los porcentajes del primero y del décimo decil; en 2010, la brecha entre estos deciles fue de 2.7 por ciento y en 2014 , la brecha fue de 4.8 por ciento.

Por su parte, en los hogares que reciben remesas internacionales también se muestra una tendencia decreciente en la distribución porcentual de los hogares a medida que se asciende en la escala de los deciles, aunque esta tendencia muestra una caída más pronunciada que la observada en el caso de los hogares receptores de remesas nacionales. Es decir, como en el caso anterior, en los deciles de menor ingreso también se concentran los hogares receptores de remesas internacionales. Estos resultados son consistentes con lo mencionado en investigaciones previas; por ejemplo, Campos y Sobarzo (2014) encontraron que los hogares del primer decil recibían mayor cantidad de remesas internacionales y que paulatinamente iba disminuyendo la cantidad de remesas recibidas conforme aumentaba el decil de ingreso. También Canales (2006) encuentra una mayor percepción de remesas en los hogares

${ }^{8}$ La construcción de los deciles de ingreso se realizó por medio del paquete estadístico Stata 12 , utilizando la variable de ingreso construida por el CONEVAL. 
con deciles de ingreso más bajos y una menor recepción en los hogares de deciles de ingreso altos. Campos y Sobarzo (2014) también encuentran que los deciles de ingreso más alto reciben menor cantidad de remesas y que, además, la proporción de estas remesas con respecto al ingreso es menor en los deciles altos.

Cuadro 7. Distribución de los hogares por decil de ingreso y condición de recepción de remesas en México 2010, 2012 y 2014

\begin{tabular}{|c|c|c|c|c|c|c|c|c|c|}
\hline \multirow{2}{*}{$\begin{array}{c}\text { DECIL DE } \\
\text { INGRESO }\end{array}$} & \multicolumn{3}{|c|}{ REMESAS NACIONALES } & \multicolumn{3}{c|}{ REMESAS INTERNACIONALES } & \multicolumn{3}{c|}{ NO RECIBE REMESAS } \\
\cline { 2 - 12 } & 2010 & 2012 & 2014 & 2010 & 2012 & 2014 & 2010 & 2012 & 2014 \\
\hline 1 & 11.6 & 12.2 & 12.8 & 14.3 & 13.9 & 14.8 & 10.3 & 10.6 & 10.3 \\
\hline 2 & 11.2 & 11.4 & 12.4 & 15.3 & 14.6 & 15.7 & 10.5 & 10.2 & 10.2 \\
\hline 3 & 10.8 & 10.7 & 10.9 & 15.3 & 13.7 & 12.9 & 10.3 & 10.4 & 10.2 \\
\hline 4 & 10.4 & 10.3 & 10.3 & 11.0 & 10.3 & 11.3 & 10.0 & 10.2 & 10.1 \\
\hline 5 & 9.4 & 10.3 & 9.8 & 10.3 & 12.5 & 9.6 & 10.5 & 10.0 & 10.1 \\
\hline 6 & 10.8 & 9.2 & 9.5 & 9.0 & 8.1 & 9.3 & 9.9 & 10.1 & 9.9 \\
\hline 7 & 9.7 & 9.1 & 8.9 & 7.7 & 8.4 & 10.0 & 9.4 & 9.5 & 9.6 \\
\hline 8 & 9.3 & 10.1 & 8.8 & 6.8 & 7.1 & 6.3 & 9.6 & 9.4 & 9.7 \\
\hline 9 & 7.8 & 9.0 & 8.7 & 5.4 & 5.8 & 5.3 & 9.4 & 9.4 & 9.5 \\
\hline 10 & 8.9 & 7.7 & 8.0 & 5.0 & 5.5 & 5.0 & 10.0 & 10.2 & 10.4 \\
\hline Total & $\mathbf{1 0 0}$ & $\mathbf{1 0 0}$ & $\mathbf{1 0 0}$ & $\mathbf{1 0 0}$ & $\mathbf{1 0 0}$ & $\mathbf{1 0 0}$ & $\mathbf{1 0 0}$ & $\mathbf{1 0 0}$ & $\mathbf{1 0 0}$ \\
\hline
\end{tabular}

Fuente: elaboración propia con datos del mCs y el CONEVAL, 2010, 2012 y 2014. Las cifras están en porcentajes.

En el cuadro 8 se observa que en los hogares no receptores de remesas la proporción de hogares pobres es un poco mayor al 42 por ciento en dos de los años de estudio. En su mayoría estos hogares se encuentran en los primeros seis deciles de ingreso, porcentaje mayor al 40 por ciento. Prácticamente, el 65 por ciento de estos hogares está ubicado en los primeros tres deciles y la proporción va disminuyendo de manera creciente, llegando a ser prácticamente cero a partir del noveno decil. Asimismo, la proporción de hogares pobres en cada decil para ambos años permaneció prácticamente inalterada.

Los hogares pobres que reciben remesas nacionales se concentran en los deciles 1 y 2 , a partir de éstos, los deciles tienen una disminución paulatina en su participación hasta llegar a cero en el último decil (cuadro 8). De los hogares pobres en el decil uno, más del 95 por ciento recibió remesas nacionales en 2010 y 2014.

Los hogares pobres que reciben remesas internacionales también se concentran en los primeros deciles y el porcentaje de dichos hogares decrece a medida que aumenta la escala de los deciles. 
236 ECONOMÍA TeORÍA Y PRÁCTICA • Nueva Época, Número especial, vol. 4, agosto 2018

Cuadro 8. Hogares pobres por decil de ingreso y condición de recepción

de remesas en México 2010 y 2014

\begin{tabular}{|c|c|c|c|c|c|c|c|c|c|c|c|c|}
\hline \multicolumn{13}{|c|}{ Recepción de remesas } \\
\hline & \multicolumn{4}{|c|}{ Remesas nacionales } & \multicolumn{4}{|c|}{ Remesas internacionales } & \multicolumn{4}{|c|}{ No recibe remesas } \\
\hline Decil & $\begin{array}{l}\text { Hogares } \\
\text { pobres }\end{array}$ & \begin{tabular}{|l|} 
Porcentaje \\
de hogares \\
pobres \\
respecto al \\
decil
\end{tabular} & \begin{tabular}{|l|} 
Hogares \\
pobres
\end{tabular} & \begin{tabular}{|l|}
$\begin{array}{l}\text { Porcentaje } \\
\text { de hogares } \\
\text { pobres } \\
\text { respecto al } \\
\text { decil }\end{array}$ \\
\end{tabular} & \begin{tabular}{|l} 
\\
Hogares \\
pobres
\end{tabular} & \begin{tabular}{|l|} 
Porcentaje \\
de hogares \\
pobres \\
respecto al \\
decil \\
\end{tabular} & \begin{tabular}{|l|} 
\\
Hogares \\
pobres
\end{tabular} & \begin{tabular}{|l|} 
Porcentaje \\
de hogares \\
pobres \\
respecto al \\
decil \\
\end{tabular} & \begin{tabular}{|l|} 
\\
Hogares \\
pobres
\end{tabular} & \begin{tabular}{|l|} 
Porcentaje \\
de hogares \\
pobres \\
respecto al \\
decil
\end{tabular} & \begin{tabular}{|l|} 
\\
Hogares \\
pobres
\end{tabular} & \begin{tabular}{|l} 
Porcentaje \\
de hogares \\
pobres \\
respecto al \\
decil
\end{tabular} \\
\hline & \multicolumn{2}{|c|}{\begin{tabular}{|l|}
2010 \\
\end{tabular}} & \multicolumn{2}{|c|}{\begin{tabular}{|l|}
2014 \\
\end{tabular}} & \multicolumn{2}{|c|}{2010} & \multicolumn{2}{|c|}{2014} & \multicolumn{2}{|c|}{2010} & \multicolumn{2}{|c|}{2014} \\
\hline 1 & 11.2 & 96.4 & 12.2 & 95.4 & 14.1 & 98.8 & 14.6 & 99.2 & \begin{tabular}{l|l}
10.0 \\
\end{tabular} & 96.5 & 9.8 & 95.6 \\
\hline 2 & 9.6 & 82.9 & 10.4 & 83.9 & 13.1 & 86.0 & 12.8 & 81.5 & 9.4 & 89.7 & 9.0 & 88.4 \\
\hline 3 & 7.5 & 64.7 & 7.6 & 69.1 & 10.5 & 68.3 & 8.5 & 66.4 & 8.0 & 77.9 & 7.7 & 75.5 \\
\hline 4 & 5.4 & 46.8 & 5.9 & 57.8 & 5.7 & 51.9 & 5.8 & 50.8 & 6.1 & 61.3 & 6.2 & 61.2 \\
\hline 5 & 3.9 & 33.2 & 4.4 & 45.3 & 4.0 & 38.6 & 3.6 & 37.6 & 4.3 & 41.5 & 4.4 & 43.2 \\
\hline 6 & 2.1 & 18.3 & 3.1 & 32.4 & 2.5 & 28.3 & 2.1 & 22.7 & 2.7 & 27.6 & 2.8 & 28.4 \\
\hline 7 & 1.6 & 14.1 & 1.9 & 21.3 & 1.4 & 18.3 & 0.9 & 9.4 & 1.4 & 15.1 & 1.4 & 14.6 \\
\hline 8 & 0.6 & 5.1 & 0.8 & 9.2 & 0.6 & 8.4 & 0.6 & 9.8 & 0.6 & 6.3 & 0.6 & 6.4 \\
\hline 9 & 0.2 & 1.4 & 0.2 & 2.0 & 0.2 & 3.3 & 0.2 & 2.9 & 0.1 & 1.1 & 0.2 & 1.9 \\
\hline 10 & 0.0 & 0.2 & 0.0 & 0.4 & 0.0 & 0.8 & 0.0 & 1.0 & 0.0 & 0.1 & 0.0 & 0.2 \\
\hline & 42.1 & & 46.5 & & 52.2 & & 49.2 & & 42.7 & & 42.1 & \\
\hline
\end{tabular}

Fuente: elaboración propia con datos del mCs y el coneVAL, 2010 y $2014 .{ }^{9}$ Las cifras están en porcentajes.

\section{REFLEXIONES FINALES}

Con la entrada en vigor del TLCAN, en México se esperaba un crecimiento económico mayor, y sostenido, en los diversos sectores de la actividad económica. No ha ocurrido en la medida esperada, sin embargo, es posible identificar efectos positivos de la apertura comercial, pese a que no formaban parte del eje central del tratado.

Uno de los posibles efectos del TLCAN que, sin proponérselo, ha ayudado a México es la entrada de divisas por concepto de remesas. A partir de la apertura económica, la emigración no puede analizarse de manera aislada y descontextualizada, ya que los emigrantes, en general, y las remesas que envían, en particular, juegan un papel significativo en el desarrollo de México (Márquez, 2007). Así, la evidencia empírica recabada en esta investigación permite concluir que los hogares que reciben remesas internacionales han disminuido sus niveles de pobreza. Este resultado contrasta con los de otras investigaciones que no identifican relaciones entre las remesas y los niveles de pobreza. A pesar de la evidencia encontrada en este análisis, sería altamente deseable que futuras investigaciones utilicen metodologías cuantitativas más sólidas, ya sea de análisis de impacto o de causalidad, para corroborar lo señalado en el presente artículo — tarea aún pendiente.

${ }^{9}$ La suma del total por año corresponde a los hogares en situación de pobreza multidimensional que se presentan en el cuadro 4. 
Entre las expectativas de la firma del TLCAN se encontraba una situación desfavorable para las localidades rurales. En este caso, la agricultura sí se ha visto perjudicada por las migraciones, pero las regiones rurales son las que tienen un mayor porcentaje de hogares con remesas internacionales, lo que se refleja en una mejora significativamente mayor en los indicadores de pobreza que los hogares urbanos y los del total nacional. Es decir, a pesar de los problemas económicos por los que ha atravesado y atraviesa el país, las remesas son un beneficio para aquellos hogares que las reciben. Con la entrada en vigor del TLCAN, las remesas internacionales han incrementado y esto ha ayudado a mejorar la situación de muchas familias que se ven perjudicadas por la pobreza, sobre todo en las zonas rurales. A pesar de que las remesas son necesarias para disminuir la pobreza, tampoco son suficientes para resolver de forma aislada dicho problema (Campos y Sobarzo, 2014).

Si bien las remesas son un factor que mejora los indicadores de pobreza, no debería ser la única fuente de ingresos que lo hiciera. Los hogares que reciben transferencias (remesas nacionales) de otros hogares dentro del país no mejoraron su situación de pobreza durante los años que comprende este estudio, lo cual muestra el terrible panorama al que dichos hogares están sujetos. Ello se puede explicar por los problemas económicos que ha presentado el país en los últimos años y que no han permitido, ni con la alternativa de migración interna, mejorar su nivel de vida. Situación que contrasta con los resultados presentados por los hogares que reciben remesas internacionales, lo cuales sí mejoraron en sus indicadores de pobreza.

Cabe señalar que los hogares que no reciben algún tipo de remesas presentan una mejor situación en los indicadores de pobreza. Se podría entender que la migración es, entonces, una alternativa de algún integrante del hogar para mejorar la condición de vida que éste tiene.

No obstante los señalamientos anteriores, resulta conveniente mencionar algunas limitaciones que se identifican en esta investigación. Puesto que el objetivo del artículo es subrayar algunos "hechos estilizados" relacionados con los niveles de pobreza y la recepción de remesas que distinguen a los hogares mexicanos a casi 25 años de la puesta en marcha del TLCAN, la naturaleza misma de este objetivo no permite profundizar en las relaciones de causalidad entre los fenómenos analizados en el artículo, a saber: TLCAN (apertura comercial), remesas y pobreza.

Es importante destacar la existencia de diversos factores que, de manera adicional a la recepción de remesas, y que no se consideraron en este estudio, podrían estar relacionados con la disminución de la pobreza, entre ellos destacan: 1) el aumento en el ingreso de los hogares pobres gracias a los apoyos gubernamentales mediante programas sociales focalizados en el combate a la pobreza; 2) el incremento en los años de escolaridad promedio de los integrantes de las familias mexicanas (Garza-Rodríguez, 2016), y 3) la depreciación del peso mexicano. 
Así mismo, resulta fundamental recalcar que es inadecuado atribuir el incremento en la recepción de remesas a un elemento en específico. La complejidad del fenómeno migratorio imposibilita aislar los distintos factores que determinan el envío de remesas, ya que éstos pueden ser de tipo económico, político o social, aunado al hecho de que la mayoría de las características particulares de los migrantes pueden no ser observadas (ambiciones individuales, apegos familiares, distintos niveles en la propensión a enviar remesas y diversos grados de arraigo en los lugares de origen y destino). El estudio de estos determinantes ha sido ampliamente documentado en la literatura académica (Rapoport y Docquier, 2006; Brown y Poirine, 2005; de la Brière et al., 2002). Por tanto, y de manera general, es posible señalar que dentro de los factores más importantes que se asocian al envío de remesas se encuentran: 1) el altruismo: el deseo del migrante por apoyar a su familia; 2) los motivos de seguridad: los migrantes envían remesas con el fin de que sus hogares disminuyan los riesgos a los que están expuestos; y 3) los motivos de inversión: gran parte de los migrantes ve a las remesas como un mecanismo para realizar inversiones productivas que les proporcione ganancias futuras (Adams, 2011). Por ende, la apertura comercial es sólo uno de los muchos factores que influyen en las remesas enviadas de un país a otro.

En los argumentos expuestos en esta investigación se está plenamente consciente de que todos estos factores en su conjunto son los que determinan el envío de remesas. Sin embargo, las reflexiones realizadas a partir del análisis estadístico de esta investigación abren distintas oportunidades en la agenda de investigación futura sobre los temas abordados. Por ejemplo, la posibilidad de aislar los efectos de la apertura comercial en la pobreza y en la dinámica de los flujos de remesas, así como en la integración de los mercados laborales internacionales en donde participan nuestros connacionales. Otra posibilidad, para extender lo expuesto en este artículo, sería utilizar técnicas econométricas robustas que permitan averiguar el efecto que la disminución de la pobreza tiene sobre el envío de remesas; es decir, realizar una investigación con una visión enmarcada en dirección contraria a lo expuesto en este trabajo.

No obstante las acotaciones anteriores y en vista de la situación actual que se está presentando en la relación económica y política entre los países de América del Norte, vale la pena preguntarse: ¿cómo reaccionarían los indicadores de pobreza en México ante una política de apertura comercial más restrictiva?, ¿cuáles serían los efectos de la construcción de un muro fronterizo para los migrantes mexicanos? Sin duda, este escenario podría implicar una reducción significativa en el envío de remesas, lo cual podría traducirse en impactos significativos en la situación de pobreza de los hogares que actualmente las reciben, especialmente aquellos hogares ubicados en zonas rurales, que se encuentran en una situación de mayor vulnerabilidad que los haría caer en situaciones de pobreza aún más intensas. 


\section{REFERENCIAS BIBLIOGRÁFICAS}

Adams, Richard (2011), "Evaluating the Economic Impact of International Remittances On Developing Countries Using Household Surveys: A Literature Review", The Journal of Development Studies, 47 (6), pp. 809-828.

Adams, Richard H.; Cuecuecha, Alfredo y Page, John (2008), Remittances, Consumption and Investment in Ghana, World Bank, Policy Research Working Paper Series, núm. 4515, Washington, Distrito de Columbia, World Bank.

Adams, Richard y Page, John (2005), "Do international migration and remittances reduce poverty in developing countries", World Development, 33 (10), pp. 1645-1669.

Albo, Adolfo y Ordaz, Juan Luis (2011), "Migración mexicana altamente calificada en EEUU y Transferencia de México a Estados Unidos a través del gasto en la educación de los migrantes", documento de trabajo núm. 11/25, BBVA Research.

Bastia, Tanja (2009), "La feminización de la migración transnacional y su potencial emancipatorio", Papeles de Relaciones Ecosociales y Cambio Global. 104, pp. 67-77.

BBVA, Research (2016), "Anuario de migración y remesas", México, Fundación Bbva Bancomer, A. C, Secretaría de Gobernación, Consejo Nacional de Población. Consultado durante junio 2017 https://www.gob.mx/cms/ uploads/attachment/file/109457/Anuario_Migracion_y_Remesas_2016. pdf

(2017), "Anuario de migración y remesas", México, Fundación BBVA Bancomer, A. C, Secretaría de Gobernación, Consejo Nacional de Población. Consultado durante octubre 2017 https://www.fundacionbbvabancomer.org/fdoc/AnuarioMigracionyRemesas2017.pdf

Brown, Richard y Poirine, Bernard (2005), “A Model of Migrant's Remittances with Human Capital Investment and Intrafimilial Transfers", International Migration Review, 39 (2), pp. 407-438.

Campos-Vazquez, Raymundo y Sobarzo, Horacio (2014), "The Effects of Emigration on Development and Fiscal Outcomes in Mexico", Migration and Border Studies, 1 (2), pp. 190-216.

Canales, Alejandro (2005), "El papel de las remesas en la configuración de relaciones familiares transnacionales", Papeles de Población, 11 (44), pp. 149-172. 
(2006), "El papel de las remesas en la reducción de la pobreza en México. Mitos y realidades", Carta Regional Económica, 19 (98), pp. 3-12. (2008), "Remesas y desarrollo en América Latina: Una relación en busca de teoría", Migración y desarrollo, 11: 5-30.

Consejo Nacional de Evaluación de la Política de Desarrollo Social (2009), “Aplicación de la metodología para la medición de la pobreza por ingresos y pruebas de hipótesis 2008". Consultado durante mayo 2017, en www. coneval.org.mx.

(2010a), Metodología para la medición multidimensional de la pobreza en México, México, D. F.

(2010), Programas de cálculo y bases de datos. Consultado durante mayo 2017, en http://www.coneval.org.mx/Medicion/MP/Paginas/Programas

BD_10_12_14.aspx

(2012), Programas de cálculo y bases de datos. Consultado durante mayo 2017, en http:/www.coneval.org.mx/Medicion/MP/Paginas/Programas

BD_10_12_14.aspx

(2014), Programas de cálculo y bases de datos. Consultado durante mayo 2017, en http://www.coneval.org.mx/Medicion/MP/Paginas/Programas

BD_10_12_14.aspx

(2014), Glosario de términos. Consultado durante julio 2017, en http:// www.coneval.org.mx/Medicion/Paginas/Glosario.aspx

Cordera, Rolando (2015), "La gran transformación del milagro mexicano. A 20 años del TLCAN: de la adopción a la adaptación”, Problemas del Desarrollo, 46 (180), pp. 11-25.

Cornelius, Wayne. (1990), Labor Migration to the United States: Development Outcomes and Alternatives in Mexican Sending Communities, Washington, Distrito de Columbia, Commission for the Study of International Migration and Cooperative Economic Development.

Cypher, James y Delgado-Wise, Raúl (2012), México a la deriva. Génesis, desempeño y crisis del modelo exportador de fuerza de trabajo, México, Miguel Ángel Porrúa.

De la Brière, Bénédicte; Sadoulet, Elisabeth; de Janvry, Alain y Lambert, Sylvie (2005), "The roles of destination, gender and household composition in explaining remittances: an analysis for the Dominican Sierra", Journal of Development Economics, 68 (2), pp. 309-328.

Delgado, Raúl y Mañán, Óscar (2005), “Migración México-Estados Unidos e integración económica", Política y Cultura, 23, pp. 9-23. 
Díaz, Alejandro (2009), "La crisis económica del 2009, las remesas y el desempleo en el área del TLCAN", Ra-Ximhai Revista de Sociedad, Cultura y Desarrollo Sustentable, 5 (1), pp. 39-48.

Durand, Jorge (2016), Historia mínima de la migración México-Estados Unidos, México, El Colegio de México.

Durand, Jorge y Massey, Douglas (1992), “Mexican Migration to the United States: A Critical Review, Latin American Research Review, 27, pp. 3-42.

Escobar, Agustín y Martínez, María de la O. (1990), Small-scale Industry and International Migration in Guadalajara, Mexico, (Documento de trabajo núm. 53). Washington, Distrito de Columbia, Commission for the Study of International Migration and Cooperative Economic Development.

García, M. Cecilia y Garro, Nora (2016), "Migración interna reciente. Factores determinantes en México 2012", en Llamas, Ignacio y Garro, Nora, Estado, reformas gubernamentales y desigualdad en los ingresos laborales (pp. 181-214), Tirant lo Blanch.

García-Zárate, Teresa (2015), "Impacto de las remesas internas y externas en la reducción de la pobreza en México: Un análisis a nivel de viviendas a partir de técnicas de Propensity Score Matching (PSM)", Papeles de Población, 21 (86), pp. 105-145.

Garza-Rodríguez, Jorge (2016), "Los determinantes de la pobreza en los estados mexicanos en la Frontera norte con Estados Unidos", Estudios Fronterizos, 17 (33), pp. 1-19.

Harris, John y Todaro, Michael (1970), "Migration, Unemployment and Development: A Two-Sector Analysis", American Economic Review, 60, pp. 126-142.

Herrera, Fernando (2016), "La remesodependencia de la economía mexicana: remesas, IED, turismo y petróleo en tiempos del TLCAN", Revista POLIS, 12 (1), pp. 45-83.

INEGi (2010), Módulo de Condiciones Socioeconómicas. Microdatos. Consultado en mayo 2017, en http://www.beta.inegi.org.mx/proyectos/enchogares/ modulos/mcs/2010/default.html (2012), Microdatos, consultado en mayo 2017, en http://www.beta.inegi. org.mx/proyectos/enchogares/modulos/mcs/2012/default.html (2014), Microdatos, consultado en mayo 2017, en http://www.beta.inegi. org.mx/proyectos/enchogares/modulos/mcs/2014/default.html 
(2010), Encuesta Nacional de Ingresos y Gastos de los Hogares, Microdatos, consultados en mayo 2017, en http://www.beta.inegi.org.mx/proyectos/enchogares/regulares/enigh/tradicional/2010/default.html (2012), Microdatos, consultados en mayo 2017, en http://www.beta.inegi. org.mx/proyectos/enchogares/regulares/enigh/tradicional/2012/default.html (2014), Microdatos, consultados en mayo 2017, en http://www.beta. inegi.org.mx/proyectos/enchogares/regulares/enigh/tradicional/2014/default.html

Lira, María G.; Robson, James P. y Klooster, Daniel J. (2016), “Can indigenous transborder migrants affect environmental governance in their communities of origin ? Evidence from Mexico", Population and Environment, 37 (4), pp. 464-478.

Loza Torres, Mariela; Vizcarra Bordi, Ivonne; Lutz Bachère, Bruno y Quintanar Guadarrama, Eduardo (2007), "Jefaturas de hogar. El desafío femenino ante la migración transnacional masculina en el sur del Estado de México", Migraciones Internacionales, 4 (2), pp. 33-60.

Márquez, Humberto (2007), "Migración y desarrollo en México: entre la exportación de la fuerza de trabajo y la dependencia de remesas", Región y Sociedad, XIX (39), pp. 3-30.

Massey, Douglas (2015), “A Missing Element in Migration Theories”, Migration Letters, 12 (3), pp. 279-299.

Massey, Douglas; Alarcón, Rafael; Durand, Jorge y González, Humberto (1987), Return to Aztlan: The Social Process of International Migration from Western Mexico, Estados Unidos, University of California Press.

Massey, Douglas; Arango, Joaquin; Graeme, Hugo; Kouaouci, Ali; Pellegrino, Adela y Taylor, Edward (1993), "Theories of International Migration: A Review and Appraisal", Population and Development Review, 19 (3), pp. 431-466.

McKenzie, David J. (2008), “A Profile of the World's Developing Country International Migrants", Population and Development Review, 10, pp. 177240.

Mendoza, Jorge y Calderón, Cuauhtémoc (2006), "Impactos regionales de las remesas en el crecimiento económico de México", Papeles de Población, 50, pp. 197-221.

Mora, Jorge y Taylor, J. Edward (2006), "Determinants of Migration, Destination, and Sector Choice: Disentangling Individual, Household, and Communi- 
ty Effects", International Migration, Remittances, and the Brain Drain, pp. 21-52.

Mora, Jorge y López Feldman, Alejandro (2010), "El efecto potencial de las remesas en la pobreza y la desigualdad", Panorama Económico, VI (11), pp. 63-82.

Mora, Jorge y Arellano, Jesús (2016), "Las remesas como determinantes del gasto en las zonas rurales de México", Estudios Fronterizos, 17 (33), pp. 1-27.

Olivié, Iliana; Ponce, Juan y Onofa, Mercedes (2008), Estudio Elcano 1. Remesas, pobreza y desigualdad: el caso de Ecuador, Madrid, Real Instituto Elcano.

Organización Internacional del Trabajo (OIT) (2005), "Migraciones internacionales, remesas y mercado laboral: la situación de América Latina y el Caribe", Panorama Laboral 2005: América Latina y el Caribe, Lima, Oficina Regional para América Latina y el Caribe, pp. 41-62.

Pardo, Ana y Dávila, Claudio (2017), "Migración y desarrollo. Características de los hogares y uso de las remesas internas e internacionales en México", Revista Desarrollo y Sociedad, 78, pp. 131-141.

Pellegrino, Adela (2003), La migración internacional en América Latina. Tendencias y perfiles de los migrantes, Santiago de Chile, Cepal y Organización Internacional para las Migraciones (OIM).

Programa de las Naciones Unidas para el Desarrollo (PNUD) (2007), Informe sobre desarrollo humano México 2006-2007. Migración y desarrollo humano, México, Ediciones Mundi-Prensa.

Rapoport, Hillel y Docquier, Frederic (2006), "The Economics of Migrants Remittances", Handbook of the Economics of Giving, Altruism and Reciprocity, 2, pp. 1135-1198.

Retamoza López, Arturo y Alonso Bajo, Rosario (2014), "Rendimientos a la educación y determinantes del mercado laboral en la Educación Superior en México: la nueva formación de recurso humano calificado", Investigaciones de Economía de la Educación, 9, pp. 879-894.

Samuelson, Paul (1939), "Interactions between the Multiplier Analysis and the Principle of Acceleration", Review of Economic Statistics, 21, pp. 7578.

Stark, Oded (1991), The Migration of Labor. Cambridge, MA, Blackwell University Press. 
Taylor, Edward (1999), "The New Economics of Labor Migration and the Role of Remittances in the Migration Process", International Migration, 37 (1), pp. 63-88.

Taylor, Edward y Castelhano, Michael (2016), "Economic impacts of migrant remittances", en International Handbook of Migration and Population Distribution, Springer Netherlands, pp. 525-541.

Taylor, Edward J.; Mora, Jorge; Adams, Richard y López-Feldman, Alejandro (2008), "Remittances, Inequality and Poverty: Evidence from Rural Mexico", en De Wind, J. y Holdaway, J. (eds.), Migration and Development Within and Across Borders: Research and Policy Perspectives on Internal and International Migration, Ed. IOM and SSRC.

Todaro, Michael (1969), "A Model of Labor Migration and Urban Unemployment in Less Developed Countries", The American Economic Review, 59, pp.138-148.

Tuirán, Rodolfo y Ávila, José Luis (2013), "Migración calificada entre México-Estados Unidos: Desafíos y opciones de política", Migración y Desarrollo, 11 (21), pp. 43-63.

Woodruff, Cristopher y Zenteno, Rene (2007), "Migration Networks and Microenterprises in Mexico", Journal of Development Economics, 82 (2), pp. 509-528.

Yang, Dean (2011), “Migrant Remittances”, Journal of Economic Perspectives, 25 (3), pp. 129-152.

Yúnez-Naude, Antonio y Taylor, Edward J. (2001), “The Determinants of Nonfarm Activities and Incomes of Rural Households in Mexico, with Emphasis on Education", World Development, 29 (3), pp. 561-572. 